\title{
Assessment of the Kempe Family Stress Inventory in self-care post-restrain schizophrenia
}

\author{
Ah.Yusuf $^{1}$, Muhammad Suhron ${ }^{2}$, Rika Subarniati ${ }^{3}$ \\ ${ }^{1}$ Faculty of Nursing, Universitas Airlangga, Indonesia \\ ${ }^{2}$ Doctoral Degree Program, Faculty of Public Health Universitas Airlangga, Indonesia \\ ${ }^{3}$ Faculty of Public Health Universitas Airlangga, Indonesia
}

\begin{tabular}{l} 
Article Info \\
\hline Article history: \\
Received Feb 11, 2019 \\
Revised Apr 12, 2019 \\
Accepted May 16, 2019 \\
\hline
\end{tabular}

\section{Keywords:}

Experience

Post-restrain

Schizophrenia

Self-care

Stress

\begin{abstract}
Basic Health Research stated that the prevalence of schizophrenia in the Indonesian population in 2018 showed schizophrenia was seven per mile; previously only 1.7 permil. The aim of study to explain stress reaction and experience families who have people with schizophrenia post-restrain. The Methods A total of 135 families who have people with schizophrenia post-restrain October to December 2018. This research was Mix Method employed Sequential Explanatory design. the research instrument used was The Kempe Family Stress Inventory (KFSI) and using in-depth interview. Results of study described a stress reaction in families normal was 43.48 ( $S . D=5.6)$, mild was 34.33 (S.D=4.7) while severe was $56.45(S . D=4.45)$. The psychological burden was expressed by families in the form of fear and worry. Reaction to high stress and family experience lacking in self-care of people with post-restrain schizophrenia.
\end{abstract}

Copyright (c) 2019 Institute of Advanced Engineering and Science. All rights reserved.

\section{Corresponding Author:}

Muhammad Suhron,

Doctoral Degree Program, Faculty of Public Health, Universitas Airlangga,

Indonesia.

Email: dsuhron@yahoo.co.id

\section{INTRODUCTION}

The psychological burden was expressed by families in the form of fear and worry to treat Schizophrenia. family stress reaction parent beaten of deprived schizophrenia and substance abuse history and multiple stress [1]. Self-care is the basic ability of humans to meet their needs to maintain life. health. in accordance with health conditions [2-3]. Families have several important reasons for the treatment of schizophrenia. as families are most associated with schizophrenia. families are considered to be most aware of the condition of family members who experience schizophrenia [4-5].

Base On World Health Organization (WHO) data, four people in the world at least one have mental problems. It is estimated there are around 450 million people in the world who have mental health problems [4-5]. The results of the Basic Health Research stated that the prevalence of severe mental disorders in the Indonesian population was $0.17 \%$ and the prevalence of mental disorders in East Java in severe mental disorders (psychosis/schizophrenia) was $0.22 \%$ and mental-emotional disorders at 6.5\% [5]. The results of the basic health research in 2018 showed schizophrenia 7 per mile previously only 1.7 permil. Mean while. the East Java Provincial Health Office recorded at least 731 people suffering from mental disorders in 26 districts/cities [5]. From the preliminary study conducted on October 18. 2018. the family experience of questionnaires. Family stress reaction parent beaten of deprived schizophrenia and substance abuse history and multiple stress reaction in biological and psychological matters such as expressed by families in the form of fear and worry to treat Schizophrenia. Base on the data it its known that Schizophrenia post restrain is the highest cause of in East Java. 
The Government made effort have been carried out to help people with mental disorders to get appropriate awards in accordance with their dignity and human dignity. The 2014 Indonesia Free Pasung Program was revised to become the Free Indonesia 2019 Program so that Indonesia in determining the achievement of targets is still there for another 5 years or even faster because this process is still ongoing with commitments from the central government and provincial and city/regency governments [4-5]

\section{RESEARCH METHOD}

This study was Mix Method employed Sequential Explanatory design. Research variables are stress reactions on family and family experiences. Target participant who treating post restrains schizophrenia in East Java Indonesia from October to December 2018. Total 135 families were used simple random sampling technique who treating post restrain schizophrenia. Step 1 explorative with questionnaire and step 2 explanation three biggest themes of finding the study in step 1. The research instrument used was The Kempe Family Stress Inventory with The sensitivity of the KFSI was calculated at $80 \%$ [6]. The specificity was $89.4 \%$, the positive predictive value was $52.5 \%$. Negative predictive value was $96.8 \%$. Power analysis used the sample size was calculated using. The sample size are: a) The power of a statistical test (1- $\beta)$. b) Level of significance $(\alpha)$, and the population effect size $(\gamma)$. Therefore. the sample size in this study has estimated the significance at 0.05 a power of 0.80 and the small effect size 0.25 requiring a sample size of 135 families for the study. The questionnaire of this study was developed by the researcher based on a literature review of The Kempe Family Stress Inventory with. The instruments included 10 item: a) Parent beaten or deprived. b) Parent has criminal or mental illness record or substance abuse history. c) Parent suspected of abuse in the past. d) Parent with isolation, low self-esteem or depression. e) Multiple stresses or crises. f) Violent temper outbursts. g) Rigid, unrealistic expectation. h) Harsh punishment. i) Child difficult and/or provocative or perceived to be by parent. j) Unwanted or at risk for poor bonding. The Kempe Family Stress Inventory consisted of 10 items a third degrees were normal. Mild (rate as 5 if one or more applies). Severe (rate as 10 if one or more applies). The sensitivity of the KFSI was calculated at $80 \%$. The specificity was $89.4 \%$. the positive predictive value was $52.5 \%$. Negative predictive value was $96.8 \%$ [6]. After that, the back-translation methods were used by three bilingual translators in this study.

\section{RESULTS AND DISCUSSIONS}

\subsection{Step 1 explorative with a questionnaire}

Step 1 explorative data as demographic data. Family stress reaction treating post restrain schizophrenia in self-care used was the Kempe Family Stress Inventory. Demographic data is shown Table 1.

Table 1. Demographic data

\begin{tabular}{cc}
\hline Characteristics Family N (135) & $\mathrm{N}=\%$ \\
\hline Gender & $58(43)$ \\
Male & $77(57)$ \\
Female & \\
Age (M) & 23.20 years \\
Carer & 22.40 years \\
Living in one house & \\
Marital status & $79(59)$ \\
Married & $56(41)$ \\
Divorced / never married / widow & 1.4 years \\
Duration of illness (M) & $122(90)$ \\
Employment & $13(10)$ \\
Full time / part time & \\
Unemployed / retired / student & $25(18.5)$ \\
Education & $23(17)$ \\
Primary School & $87(64)$ \\
Junior high schools & \\
Senior high schools & $6(4)$ \\
Residences & $129(96)$ \\
Urban & \\
Rural & $12(10)$ \\
Couples & $82(60)$ \\
Parents & $9(6)$ \\
Children & \\
Sibling & \\
\hline
\end{tabular}

Int. J. Public Health Sci. Vol. 8, No. 2, June 2019: 197 - 201 
Demographic data: the mean age carer 23.2 years $(S D=13.45)$ and living in one house 22.4 years $(\mathrm{SD}=12.22)$. A majority of them were Female $(\mathrm{n}=77.57 \%)$. Most Marital status divorce $(\mathrm{n}=79.59 \%)$. The mean Duration of 1.4 years $(\mathrm{SD}=0.6)$. The majority employment full time $(\mathrm{n}=122.90 \%)$. Most Education were senior high schools $(\mathrm{n}=87.64 \%)$. A majority Residences were Rural $(\mathrm{n}=129.96 \%)$. Most Relationships were Parents $(n=82.60 \%)$ respectively and it is shown in Table 1. Stres reaction is shown in Table 2.

Table 2. Stress reaction

\begin{tabular}{cc}
\hline Stress Reaction & Mean \pm SD \\
\hline Normal & $43.48 \pm 5.6$ \\
Mild & $34.33 \pm 4.7$ \\
Severe & $56.45 \pm 4.45$ \\
Parent Beaten or Deprived & $45.36 \pm 8.12$ \\
Parent has Criminal or Mental Illness Record. or Substance Abuse History & $12.34 \pm 3.7$ \\
Parent Suspected of Abuse in the Past & $7.2 \pm 1.7$ \\
Parent with Isolation. Low Self-esteem. or Depression & $4.1 \pm 1.23$ \\
Multiple Stresses or Crises & $8.1 \pm 2.4$ \\
Violent Temper Outbursts & $5.5 \pm 3.5$ \\
Rigid Unrealistic Expectation & $4.2 \pm 2.3$ \\
Harsh Punishment & $5.9 \pm 1.4$ \\
Difficult and/or Provocative or Perceived to be by Parent & $3.9 \pm 1.2$ \\
Unwanted or at Risk for Poor Bonding & $3.4 \pm 1.5$ \\
\hline
\end{tabular}

Table 2 shows that the study findings revealed that the overall family stress reaction parent beaten of deprived schizophrenia average score was $45.36(\mathrm{SD}=8.12)$ and for lowest stress reaction that unwanted or at risk poor bonding average score was $3.4(\mathrm{SD}=1.5)$. The second highest stress reaction that parent has criminal or mental illness record or substance abuse history average score was $12.34(\mathrm{SD}=3.7)$. Consequently average multiple stresses or crises score was $8.1(\mathrm{SD}=2.4)$. Parent suspected of abuse in the past average score was 7.1 $(\mathrm{SD}=1.7)$ but parent with isolation. Low self-esteem or depression average score was 4.1 ( $\mathrm{SD}=1.23)$. Violent temper outbursts average score was $5.5(\mathrm{SD}=3.5)$. Rigid unrealistic expectation average score was 4.2 $(\mathrm{SD}=2.3)$. Harsh punishment average score was $5.9(\mathrm{SD}=1.4)$ and for difficult and/or provocative or perceived to be by parent average score was $3.9(\mathrm{SD}=1.2)$.

\subsection{Step 2 explanation three biggest themes that were explained in order to reflect the purpose of the study}

His study obtained three biggest themes that were explained in order to reflect the purpose of the study. Description of interview is shown in Table 3.

Table 3. Description of interview

\begin{tabular}{|c|c|c|c|c|}
\hline Session & Interview methods & Theme & Contents & Duration (mins) \\
\hline 1 & $\begin{array}{c}\text { Face to face } \\
\text { interview session }\end{array}$ & Parent Beaten or Deprived & $\begin{array}{l}\text { 1. Threatening incident } \\
\text { 2. Get physical abuse } \\
\text { 3. Get social isolation from schizophrenia }\end{array}$ & $5-10$ \\
\hline 2 & $\begin{array}{c}\text { Face to face } \\
\text { interview session }\end{array}$ & $\begin{array}{l}\text { Parent has Criminal or } \\
\text { Mental Illness Record. or } \\
\text { Substance Abuse History }\end{array}$ & $\begin{array}{l}\text { 1. Previous events of abuse } \\
\text { 2. History of the disease } \\
\text { 3. Previous criminal actions }\end{array}$ & $5-10$ \\
\hline 3 & $\begin{array}{c}\text { Face to face } \\
\text { interview session }\end{array}$ & Multiple Stresses or Crises & $\begin{array}{l}\text { 1. Fear and anxiety when caring for } \\
\text { 2. The form of burden felt when caring for } \\
\text { 3. The most stressful event when caring for }\end{array}$ & $5-10$ \\
\hline
\end{tabular}

\section{1) Parent beaten or deprived}

With regard to the theme of Parent Beaten or Deprived. as stated by the participants:

"Sometimes if the desire is not followed he is angry and threatens to hit"( $\mathrm{P} 1)$

"Other than that when schizophrenia asked about something. he threw objects near him....(P6) (P8)

"Ever hit a neighbor when asking for food and drink..." (P1)

Other Barrier related to Deprived

“When schizophrenia went on a rampage or was angry I did restrain it back” (P3)

"I help provide food and drink and take a bath if needed"(P4)

2) Parent has criminal or mental illness record. or substance abuse history

"Schizophrenia has experienced divorce with his wife. it happened about 1 year ago...." (P7) (P9)

"Schizophrenia. when fired from their work. is often daydreaming and alone. and asking for money to be able to work again.. ”(P10) 


\section{3) Multiple stresses or crises}

"Yes. when schizophrenia goes on a rampage. I ask my neighbors and other families for help in engaging in schizophrenia so as not to harm others. this makes me very stressful" (P11) (P5)

"Schizophrenia also sometimes. clothing. urinates and defecates in places so it makes me very disturbed and stressed. I am patient and resigned..." (P2)

Families stress reaction in treating schizophrenia is felt like a psychological burden showed revealed that the overall family stress reaction parent beaten of deprived schizophrenia. The psychological burden was expressed by participants in the form of fear. worry and increase blood pressure [6, 8-9]. The fear here is because coping mechanisms. for example. the client sometimes if the desire is not followed he is angry and threatens to hit will get angry and hurt others around him. Feelings of worry until the heart flutters also feel family if schizophrenia goes on. do not go back home and make mistakes outside [6-7, 9-10]. The family believes that post-restrain schizophrenia is left by work by his family. schizophrenia post restrain will run around the house. angry. and harm other people so that the perceived family is not calm while taking care of post restrain schizophrenia. Mental health of the family system approach justified under conditions of self care. and therapeutic interventions for children must. therefore. also involve parents and siblings [8-11]. Knowledge of unique family attachment patterns is useful for adapting therapeutic treatments and preventive interventions for schizophrenia and families affected by the family burden. Family members assist in caring for clients. If the family works. then other family members who help take care of client needs such as eating and drinking. The family helps meet the needs of self-care clothing [12-14]. Adolescent social relations as reported through the stigma experienced. have a negative impact on boys and girls $[11,15]$.

A majority parent has substance abuse history. Parental reports of symptoms of PTSD (Post-Traumatic Syndrome) and depression have strong negative effects on girls" outcomes. including stigma experienced. externalizing behavior. and school days rather than boys [8, 10-11, 15-16]. The perceptions of family caregivers in this area and about their free time. this can provide a broader perspective for mental health therapists. rehabilitation managers and policy makers to understand needs. overcome challenges and barriers from this family care group [11-12, 15, 17]. Researchers argue that meeting the needs of self-care for family baths helps meet the need to bathe post-restrain schizophrenia. The family revealed that post-restrain schizophrenia had a desire to take a bath and did not want to take a bath. The relationship between the general tendency to avoid actions in problem situations and the tendency to seek social transfer to overcome stress $[12,15,18]$. Assertive behavior was also found to correlate with the tendency to be involved in substitution activities. Greater willingness to display assertive behavior is observed in subjects who express a tendency to avoid thinking about problems and find active solutions in stressful situations. Therefore, the family tries to meet the needs of post-restrain schizophrenia bath so that personal hygiene in schizophrenia can be well maintained and can prevent disease. The family stated that the fulfillment of bathing needs is illustrated by bath time. bathing method. bathing place. and problems when bathing are not met. The hospital or nurse must do family coping while facing various problems in treating the client's mental disorder after post. This activity can be realized through the provision of counseling services and health care workers always control families and clients. Multiply family empowerment in managing the various burdens faced by families who care for post-mental disorders [18-20]. The need for self-care elimination in schizophrenia post-restrain helps fulfill the need for self-elimination care in schizophrenia post-restrain. Schizophrenia also sometimes urinates and defecates in places so it makes me very disturbed and stressed. I am patient and resigned. family environment interaction affects both aggressions directed outward and symptoms of mood and anxiety disorders in a specific way [20-25]. The family explained that the method of schizophrenia post-restrain removal is varied. that is by covering the soil. being given a hole. given water to wash. toilet. and indoors.

\section{CONCLUSION}

Most of the stress on families who have schizophrenia post-restrain is still showed revealed that the overall family stress reaction parent beaten of deprived schizophrenia. Majority parent has substance abuse history and multiple stress. Most family experiences with post-restrain schizophrenia are lacking in self-care to change clothes, bathe and process elimination in post-restrain schizophrenia.

\section{ACKNOWLEDGEMENTS}

We would like to appreciate those who are participating in this study. The manuscript was written in fulfillment of the requirement to obtain Doctoral degree program Public Health Faculty Airlangga University. Indonesia. The author declare that three is no conflict of interest regarding publication of this article

Int. J. Public Health Sci. Vol. 8, No. 2, June 2019: 197 - 201 


\section{REFERENCES}

[1] Hegde A, Chakrabarti S, Grover S. Caregiver distress in schizophrenia and mood disorders: the role of illness related stressors and caregiver-related factors. Nordic Journal of Psychiatry. 12 Jan. Vol 1. No 11 2019:1-9.2019

[2] Wang X, Chen Q, Yang M. Effect of caregivers" expressed emotion on the care burden and rehospitalization rate of schizophrenia. Patient Prefer Adherence. 2017 Sep. Vol. 6. No.11: 1505-1511. 2017

[3] Yu Y, Tang BW, Liu ZW, Chen YM, Zhang XY, Xiao S. Who cares for the schizophrenia individuals in rural China -A profile of primary family caregivers. J Compr Psychiatry. Jul 2018. Vol 84. No 16:47-53. 2018

[4] Hidru TH, Osman MH, Lolokote S, Li X. Extent and pattern of burden of care and its associated factors among Eritrean families of persons living with schizophrenia: a cross-sectional study. BMJ Open. Sep 2016 vol 28. No 6(9):e012127. 2016

[5] Ministry of Health. Report on Basic Health Research Results (Riskesdas) Indonesia 2018. Jakarta: Health Research and Development Agency. 2018

[6] Korfmacher J. The Kempe Family Stress Inventory: a review. Child Abuse \& Neglect. Jan 2000. Vol 24. No 1:12940. 2000

[7] Aung S, Musa RAJMA, Abdullah, A. Relationship between Coping Mechanisms to Psychosocial Stress with Blood Pressure in Young Adults: A Pilot Study. Bangladesh Journal of Medical Science. Jun 2018 Vol 17. No 3:439-445. 2018

[8] Sihyun Park, Kyung SookPark. Family Stigma: A Concept Analysis. Asian Nursing Research. Sep 2014 . Vol 8. No 3:165-171. 2014

[9] Priestley J, Mc Pherson S. Experiences of adults providing care to a partner or relative with depression: A metaethnographic synthesis. J Affect Disord. Mar 2016. Vol 1. No 192:41-9. 2016

[10] Smolak A, Gearing RE, Alonzo D, Baldwin S, Harmon S, Mc Hugh K. Social support and religion: mental health service use and treatment of schizophrenia. Community Ment Health J. Aug 2013. Vol 49. No 4:444-50.2013

[11] Tristiana, D. et al. Perceived barriers on mental health services by the family of Patients with mental illness. International Journal of Nursing Sciences 2018. Vol 5. No.1: 63-67. 2018

[12] Humm A,Kaminer D,Hardy A. Social support, exposure to violence and mental health among South African teenagers. J Child Adolesc Ment Health Mar 2018. Vol 30. No 1: 41-50. 2018

[13] Nancy G, Anjalee K, Pamela JS, Mitma MR. Relationship between parental mental health and intimate partner violence on adolescent behavior, stigma and school attendance in families rural Democratic Republic of Congo. Glob Ment Health (Camb). Feb 2018. Vol 21. No 5: 20-45. 2018

[14] Li, X. et al. The influence of marital status on the social dysfunction of schizophrenia Patients in community. International Journal of Nursing Sciences. 2015. Vol 2. No 2: 149-152. 2015

[15] Skotnik A, Samochowiec A. The effects of psychological help on assertive behaviors in family members of schizophrenia patients. Psychiatria Polska. 2018 Apr 30;52(2):275-286. https://doi.org/10.12740/PP/78414.

[16] Hatch R, Young D, Barber V, Griffiths J, Harrison DA, Watkinson P. Anxiety, Depression and Post Traumatic Stress Disorder after critical illness: a UK-wide prospective cohort study. Critical care. Nov 2018 vol. 23. No 22.1:310. 2018

[17] M Bailara K, Minois I, Zanouy L, Josse F, Rouan E, Maîtrot A, Sportich J, Roux S, Jutant A, Deloge A, Desage A, Gard S. Therapeutic education: A lever to change perceptions of bipolar disorder in family caregivers. Encephale. 2019 Feb 2. S0013-7006(19)30023-5. 2019

[18] Galatsch M, Prigerson HG, Schnepp W, Zu Sayn-Wittgenstein F Li J. Caregiver exposure to critical events and distress in home-based palliative care in Germany a cross-sectional study using the Stressful Caregiving Adult Reactions to Experiences of Dying (SCARED) scale. BMC Palliat Care. Jan 2019. Vol 18. No.1:9. 2019

[19] Cruz D, Rodriguez Y, Mastropaolo C. Perceived microaggressions in health care: A measurement study. PLoS One. Feb 2019. Vol 14. No 2.1-9. 2019

[20] Suhron, M. Nursing care of the soul: The concept of self Esteem. Mitra Wacana Media. 89-114. 2017

[21] Suhron, M. Influence On Ability Family Family Psychoeducation In Treating People With Mental Disorders Deprived Mental Illness /(Pasung). Journal of Applied Science and Research. 2017. Vol 5. No 1: 41-51. 2017.

[22] Rüsch N, Malzer A, Oexle N, Waldmann T, Staiger T, Bahemann A, Wigand ME, Becker T, Corrigan PW. Disclosure and Quality of Life Among Unemployed Individuals With Mental Health Problems: A Longitudinal Study. The Journal of nervous and mental disease. Jan 2019. Vol 1 No.3.1-5.2019

[23] Ghannam BM, Hamdan-Mansour AM, Al Abeiat DD. Psychological Correlates of Burden Among Jordanian Caregivers of Patients With Serious Mental Illness. Perspect Psychiatr Care. Oct 2017. Vol 53. No4:299-306.2017

[24] Suhron, M. Assessment Potential of Families Increasing Ability to Care for schizophrenia Post Restrain at east Java, Indonesia. Indian Journal of Public Health Research \& Development, Oct 2018, Vol. 9, No. 10.2018

[25] Suhron, M, Amir F. Reduce violent behavior schizophrenia: A new approach using LT (Laughing therapy) and DRT (Deep relaxation therapy). Indian Journal of Public Health Research \& Development. 2018, Vol 9. No. 8. 2018 